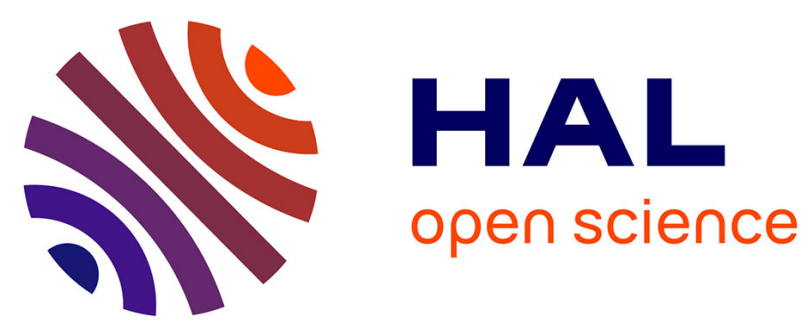

\title{
Supramolecular chirogenesis in zinc porphyrins: Complexation with enantiopure thiourea derivatives, binding studies and chirality transfer mechanism
}

Nele Konrad, Darya Meniailava, Irina Osadchuk, Jasper Adamson, Mohammed Hasan, Eric Clot, Riina Aav, Victor Borovkov, Dzmitry Kananovich

\section{To cite this version:}

Nele Konrad, Darya Meniailava, Irina Osadchuk, Jasper Adamson, Mohammed Hasan, et al.. Supramolecular chirogenesis in zinc porphyrins: Complexation with enantiopure thiourea derivatives, binding studies and chirality transfer mechanism. Journal of Porphyrins and Phthalocyanines, 2020, 24 (05n07), pp.840-849. 10.1142/S108842461950192X . hal-02617498

\section{HAL Id: hal-02617498 \\ https://hal.umontpellier.fr/hal-02617498}

Submitted on 29 May 2020

HAL is a multi-disciplinary open access archive for the deposit and dissemination of scientific research documents, whether they are published or not. The documents may come from teaching and research institutions in France or abroad, or from public or private research centers.
L'archive ouverte pluridisciplinaire HAL, est destinée au dépôt et à la diffusion de documents scientifiques de niveau recherche, publiés ou non, émanant des établissements d'enseignement et de recherche français ou étrangers, des laboratoires publics ou privés. 


\title{
Supramolecular chirogenesis in zinc porphyrins: complexation with enantiopure thiourea derivatives, binding studies and chirality transfer mechanism
}

\author{
Nele Konrada , Darya Meniailavaa,b, Irina Osadchuka, ${ }^{a, c}$, Jasper Adamson ${ }^{d}$, Mohammed \\ Hasan $^{\mathrm{e}}$, Eric $\mathrm{Clot}^{\mathrm{c}}$, Riina Aav ${ }^{\mathrm{a}}$, Victor Borovkov ${ }^{\mathrm{a}, \mathrm{e}}$, and Dzmitry Kananovich ${ }^{* a}$
}

dedicated to Professor Roberto Paolesse on the occasion of his $60^{\text {th }}$ birthday

a Tallinn University of Technology, School of Science, Department of Chemistry and Biotechnology, Akadeemia tee 15, 12618 Tallinn, Estonia

${ }^{\mathrm{b}}$ Belarusian State University, Faculty of Physics, Nezavisimosti av. 4, 220030 Minsk, Belarus

' ICGM, Univ. Montpellier, CNRS, ENSCM, Montpellier, France

${ }^{\mathrm{d}}$ National Institute of Chemical Physics and Biophysics, Akadeemia tee 23, 12618 Tallinn, Estonia

e South-Central University for Nationalities, College of Chemistry and Materials Science, \#182 Minzu RD, Hongshan District, Wuhan, Hubei province 430074, China.

\begin{abstract}
Complexation of three $(1 R, 2 R)$-2-aminocyclohexyl arylthioureas $($ aryl $=3,5-$ bis(trifluoromethyl)phenyl; phenyl; 3,5-dimethylphenyl) as the guests to ZnTPP and ZnOEP hosts has been studied by means of UV-Vis, CD spectroscopies and computational simulation. The complexation proceeds via coordination of the primary amino group to the zinc ion of the metalloporphyrin and induces a moderate circular dichroism signal in the Soret band of the porphyrins. The association constants increase with larger electronwithdrawing properties of the porphyrin host and larger electron-donating ability of the guest, indicating predominantly electrostatic (Lewis acid-base) character of the complexation. Computational study of the $(1 R, 2 R)$-2-aminocyclohexyl-(3,5-bis(trifluoromethyl)phenyl)thiourea and ZnTPP complex revealed slight asymmetric distortion of the porphyrin plane caused by the chiral guest and additional $\pi$ - $\pi$ interactions between the host and guest molecules. Calculated CD spectrum for the same system reproduces the experimentally observed.
\end{abstract}

KEYWORDS: porphyrin, thiourea, chiral amine, chirality, circular dichroism, host-guest binding, TD-DFT

*Correspondence to: Victor Borovkov, email: victor.borovkov@scuec.edu.cn; Dzmitry Kananovich, email: dzmitry.kananovich@taltech.ee

\section{INTRODUCTION}

Due to a unique set of physicochemical properties, such as optical characteristics, facile synthetic modification of molecular structure and a prominent ability for reversible binding of various organic and inorganic compounds, metalloporphyrins are often used as a key element in chemical sensors [1]. Besides detection of small molecules in gas phase and in solution [2], the 
porphyrin-based supramolecular systems have found a wide application as various chirality probes [3]. Remarkably, intrinsically achiral metalloporphyrins are able to exhibit optical activity by inducing circular dichroism (CD) signal in the absorption region of the porphyrin Soret band by axial coordination of a chiral guest. In general, the mechanism of chirality transfer is based on either electronic transition coupling between the corresponding chromophore moieties of host and guest or asymmetric puckering of the porphyrin plane $[4,5]$. This chirality transfer phenomenon (termed supramolecular chirogenesis) $[5,6]$ has been successfully used for determination of the absolute configuration of versatile enantiopure compounds, e.g. amines [6, 7], alcohols [8] and amino acid derivatives [4, 9]. For zinc porphyrin-based systems, primary amines are particularly privileged sensing molecules due to their strong binding affinity and well understood mechanism of chirality transfer $[3 b, 5,6]$. Although quite a large scope of different chiral amines has been explored to date, the interaction of porphyrins with functionalized amine scaffolds, which can act as complex bidentate ligands and possess additional properties such as catalytic activity, has been previously studied only on a limited number of chiral compounds [10] and needs to be expanded.

As a part of our studies towards development of new porphyrin-based sensing systems for the detection of polyfunctionalized chiral organic molecules, which are present in the environment as chiral pollutants, the chirality transfer phenomenon in the host-guest assemblies consisting of (1R,2R)-2-aminocyclohexyl arylthioureas 1a-c (Scheme 1) to ZnTPP and $\mathrm{ZnOEP}$ needs to be comprehensively investigated. Since the pioneering work of Takemoto et al. [11], bifunctional compounds of type $\mathbf{1}$ with hydrogen-bonding thiourea moiety and neighbouring basic amine site, have been intensively used as chiral organocatalysts [12].

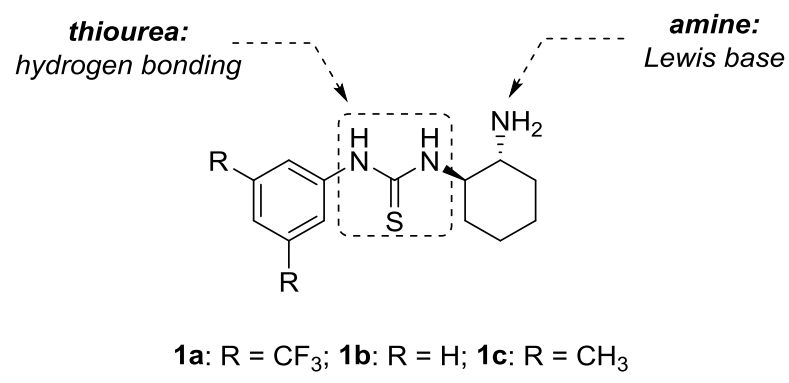

Scheme 1. Thioureas 1a-c with bifunctional properties used in this study.

In view of the extensively exploited hydrogen-bond donating properties of thioureas in asymmetric catalysis $[12,13]$ and crystal engineering [14], compounds 1 represent a potentially important class of bifunctional chiral axial ligands for zinc porphyrins, with previously unexplored effect of the thiourea function onto chirogenic process induced by a chiral amine. Here, we present the first report on supramolecular interactions and chirality transfer phenomena in the host-guest system of 1 and zinc porphyrins, studied by means of UV-Vis and CD spectroscopy. The results have been rationalized with the assistance of computational studies, which allowed us to elucidate the origin of the observed chirogenic process and induced $\mathrm{CD}$, as well as to propose a plausible structure of the host-guest complex formed in solution.

\section{EXPERIMENTAL}

\section{General methods}

${ }^{1} \mathrm{H}$ NMR spectra were recorded on either a Bruker Avance III $400 \mathrm{MHz}$ or a Bruker Avance III $800 \mathrm{MHz}$ spectrometers. The chemical shifts $(\delta)$ are reported in ppm and referenced to $\mathrm{CHCl}_{3}$ residual peak at $7.26 \mathrm{ppm}$ for ${ }^{1} \mathrm{H} \mathrm{NMR}$, and $\mathrm{CDCl}_{3}$ peak 
at $77.16 \mathrm{ppm}$ for ${ }^{13} \mathrm{C}$ NMR. UV-Vis absorption spectra were recorded on a Jasco V-730 double-beam spectrophotometer in a $1 \mathrm{~cm}$ thermally stabilized screw cap quartz cuvettes with a septum cap. CD spectra were recorded on a Jasco J-1500 spectrophotometer in a $1 \mathrm{~cm}$ screw cap quartz cuvette in analytical grade $\mathrm{CH}_{2} \mathrm{Cl}_{2}$ at $20{ }^{\circ} \mathrm{C}$. Data acquisition was performed in 410-460 nm range for ZnTPP and (390-440 nm for ZnOEP) with scanning rate $10 \mathrm{~nm} \cdot \mathrm{min}^{-1}$, bandwidth $2.6 \mathrm{~nm}$, response time $4 \mathrm{~s}$, and accumulations in 4 scans.

\section{Materials}

Zinc(II) tetraphenylporphyrin (ZnTPP) and octaethylporphyrin free base $\left(\mathrm{H}_{2} \mathrm{OEP}\right)$ were purchased from PorphyChem. Other chemicals and solvents were purchased from commercial suppliers and used as received. Zinc(II) octaethylporphyrin (ZnOEP) was prepared by insertion of zinc ion into octaethylporphyrin free base by the standard procedure [15] and its purity was confirmed by ${ }^{1} \mathrm{H}$ NMR.

$(1 R, 2 R)$-2-aminocyclohexyl thioureas 1a-c were prepared as described in the literature from $(1 R, 2 R)-1,2-$ diaminocyclohexane and corresponding aryl isothiocyanates [16]. (1S,2S)-enantiomer of 1a was prepared from (1S,2S)-1,2diaminocyclohexane correspondingly. The NMR spectral data for $\mathbf{1 a}$ and $\mathbf{1 b}$ were previously reported [16b]. NMR data for 1c have not been previously described.

1-((1R,2R)-2-aminocyclohexyl)-3-(3,5-dimethylphenyl)thiourea (1c): ${ }^{1} \mathrm{H}$ NMR $\left(\mathrm{CDCl}_{3}, 800 \mathrm{MHz}, 298 \mathrm{~K}\right) \delta=6.82$ (br s, $3 \mathrm{H}), 6.15$ (br s, 1H), 3.10 (br s, 1H), 2.34-2.62 (br m, 1H), 2.28 (br s, 6H), 2.06-2.20 (br m, 1H), 1.88-1.97 (br m, 1H), 1.661.78 (br m, 2H), 1.59 (br s, 2H), 1.27-1.39 (br m, 1H), 1.16-1.27 (br m, 2H), 0.95-1.16 (br m, 1H), NH proton is missed due to severe line broadening. ${ }^{13} \mathrm{C} \mathrm{NMR}\left(\mathrm{CDCl}_{3}, 201.2 \mathrm{MHz}, 298 \mathrm{~K}\right) \delta=180.76,139.96,136.24,128.75,125.60,61.91,55.92$, $35.59,32.14,25.02,24.94,21.40$. Signal assignment is given in the Supporting Information.

\section{Spectroscopic binding study}

All the solutions were prepared and mixed by using properly calibrated analytic glassware (Hamilton ${ }^{\circledR}$ Gastight syringes, volumetric flasks). All weights were balanced with a Radwag MYA 11.4 microbalance (accuracy $\pm 6 \mu \mathrm{g}$ ). The concentration of zinc porphyrins was held constant throughout the titration sequence. The titration data were fitted globally using online software Bindfit (http://supramolecular.org) [17, 18].

$\mathrm{UV}-\mathrm{Vis}$ spectrophotometric titration experiments were performed in analytical grade $\mathrm{CH}_{2} \mathrm{Cl}_{2}$. To a solution of zinc porphyrin, a solution of thiourea 1a-c (dissolved in a stock solution of the host to keep the concentration of the host constant) was added portion-wise using a gastight syringe at $20^{\circ} \mathrm{C}$. The changes in bathochromic shift of the Soret band were monitored at different concentrations of the guest 1a-c. The details of the titration experiments, obtained spectra, absorptions values, concentrations, fittings and residual analysis are presented in the Supporting Information.

${ }^{1} \mathrm{H}$ NMR titration experiments were performed in $\mathrm{CDCl}_{3}$ at $800 \mathrm{MHz}$ instrument. To a solution of porphyrin $\mathrm{ZnTPP}$, a solution of tetramethylthiourea (dissolved in a stock solution of the host to keep the concentration of the host constant) was added portion-wise using a gastight syringe. NMR tube was thermally equilibrated $\left(20^{\circ} \mathrm{C}\right)$ after each addition prior to acquisition. The details of the titration experiments, chemical shifts, concentrations, fittings, and residuals analysis are given in the Supporting Information.

\section{Computational details}


Conformation search for 1a·ZnTPP complex was performed as follows. Five dihedral angles in thiourea 1a, which correspond to rotation of the phenyl and cyclohexane moieties as well as two $\mathrm{N}-\mathrm{H}$ and $\mathrm{C}=\mathrm{S}$ fragments around the corresponding single bonds were varied and structures optimized for the complex of unsubstituted zinc porphyrin and 1a (Fig. S24, Supporting Information). Subsequently, four phenyl substituents were attached perpendicularly to the porphyrin plane for the six lowest-energy conformers. This approach has been used before [19], and can be applied due to the low rotation barrier of phenyl [20].

The initial geometry optimization was performed with Turbomole 6.5 [21] using PB86 functional [22, 23a] with D3 dispersion correction [23b], def2-SV(P) basis set [23c] and resolution of identity (RI) approximation [24]. The geometries of the six lowest-energy conformers were re-optimized with Gaussian 16 [25] using B3LYP functional [22, 26a-c] with D3(bj) dispersion correction [26d] and cc-pVDZ basis set [27], since the B3LYP functional with a double zeta basis set was previously successfully used for optimization of porphyrin systems [28]. The geometry optimization and re-optimization were done in the gas phase. Frequencies were calculated with the same level of theory as the geometry optimization, to confirm that the structures are minima on the potential surface. Final single-point energy calculations were performed with $\omega B$ 97X-D functional [29], cc-pVTZ basis set [27] and the Solvation Model Density (SMD) approximation [30] to model $\mathrm{CH}_{2} \mathrm{Cl}_{2}$.

The CD spectra were calculated using the re-optimized geometries and Gaussian 16 [25]. For CD spectra calculations, the TD-DFT method [31], $\omega$ B97X-D/cc-pVTZ level of theory and SMD approximation were used, since $\omega$ B97X-D was previously successfully applied for UV-Vis and ECD spectra simulations [28a, 32]. For spectra simulations, the Gaussian profiles and rotatory strengths calculated on the basis of dipole velocity formalism were used. The bandwidth values of 0.04 $\mathrm{eV}$ and $0.06 \mathrm{eV}$ were taken for electronic absorption and $\mathrm{CD}$ spectra, respectively.

\section{RESULTS AND DISCUSSION}

\section{Binding studies}

Generally, primary aliphatic amines strongly bind to zinc porphyrin ZnTPP with association constant $\left(K_{\mathrm{a}}\right)$ values of 6000$22000 \mathrm{M}^{-1}$ in chloroform [33]. However, in view of the known ability of thioureas to coordinate zinc cation [34] and its strong electron-donating character [35], sulfur atom in 1a-c can act as a competitive binder. Therefore, at the outset of our studies the strength of $\mathrm{Zn}$...S ion-dipole interaction had to be evaluated as well. Coordination of some sulfur-centered nucleophiles to zinc porphyrins [36a-c] and related phthalocyanines [36d] have been reported with essentially a large $K_{\mathrm{a}}$ value $(2.5 \pm 0.2)$ $\times 10^{4} \mathrm{M}^{-1}$ observed for binding the $\mathrm{HS}^{-}$anion to zinc protoporphyrin IX [36c]. Compared to anionic thiolate, neutral tetramethylthiourea resulted in a rather small $K_{\mathrm{a}}$ value $\left(12.0 \pm 0.1 \mathrm{M}^{-1}\right.$ at $\left.298 \mathrm{~K}\right)$ for 1:1 complex with ZnTPP in benzene [37]. This agrees with a large electrostatic contribution to the binding of donor ligands to ZnTPP, as was established by Vogel and Searby [37]. The binding of electron-donating guests increases in the order of $\mathrm{S}<\mathrm{O}<\mathrm{P}<\mathrm{N}$.

According to our results, a weak interaction between tetramethylthiourea and $\mathrm{ZnTPP}$ was also observed in $\mathrm{CDCl}_{3}$ as a solvent. The change in the chemical shifts of ZnTPP upon addition of tetramethylthiourea was monitored by ${ }^{1} \mathrm{H}$ NMR. It was found that two resonances of ZnTPP at $\delta 8.95$ and $8.23 \mathrm{ppm}$, corresponding to the signals of pyrrole and $o$-phenyl protons respectively, noticeably shifted upfield upon increasing the concentration of guest tetramethylthiourea. However, the change was small and did not exceed $0.012 \mathrm{ppm}$, giving an estimation of $K_{\mathrm{a}}=17 \mathrm{M}^{-1}$ (at $293 \mathrm{~K}$ ), which is in agreement with the value in benzene reported by Vogel [37]. These results clearly indicate that the coordination of thiocarbonyl group to ZnTPP is weak. Therefore, in the case of the bifunctional ligands $\mathbf{1}$, binding via a primary amine functionality is expected to dominate. 
Indeed, in UV-Vis spectra noticeable bathochromic shifts of the porphyrin Soret and Q bands as well as a clear isosbestic point at $424 \mathrm{~nm}$ were observed upon addition of amino-functionalized thiourea 1a to a solution of $\mathrm{ZnTPP}^{\text {in }} \mathrm{CH}_{2} \mathrm{Cl}_{2}(\mathrm{Fig}$. 1). The curve fitting of the absorbance change in the region of the most intense Soret band with the 1:1 binding isotherm was performed (see Supporting Information), yielding a $K_{\mathrm{a}}$ value of $(2.30 \pm 0.04) \times 10^{3}$ at $293 \mathrm{~K}$.
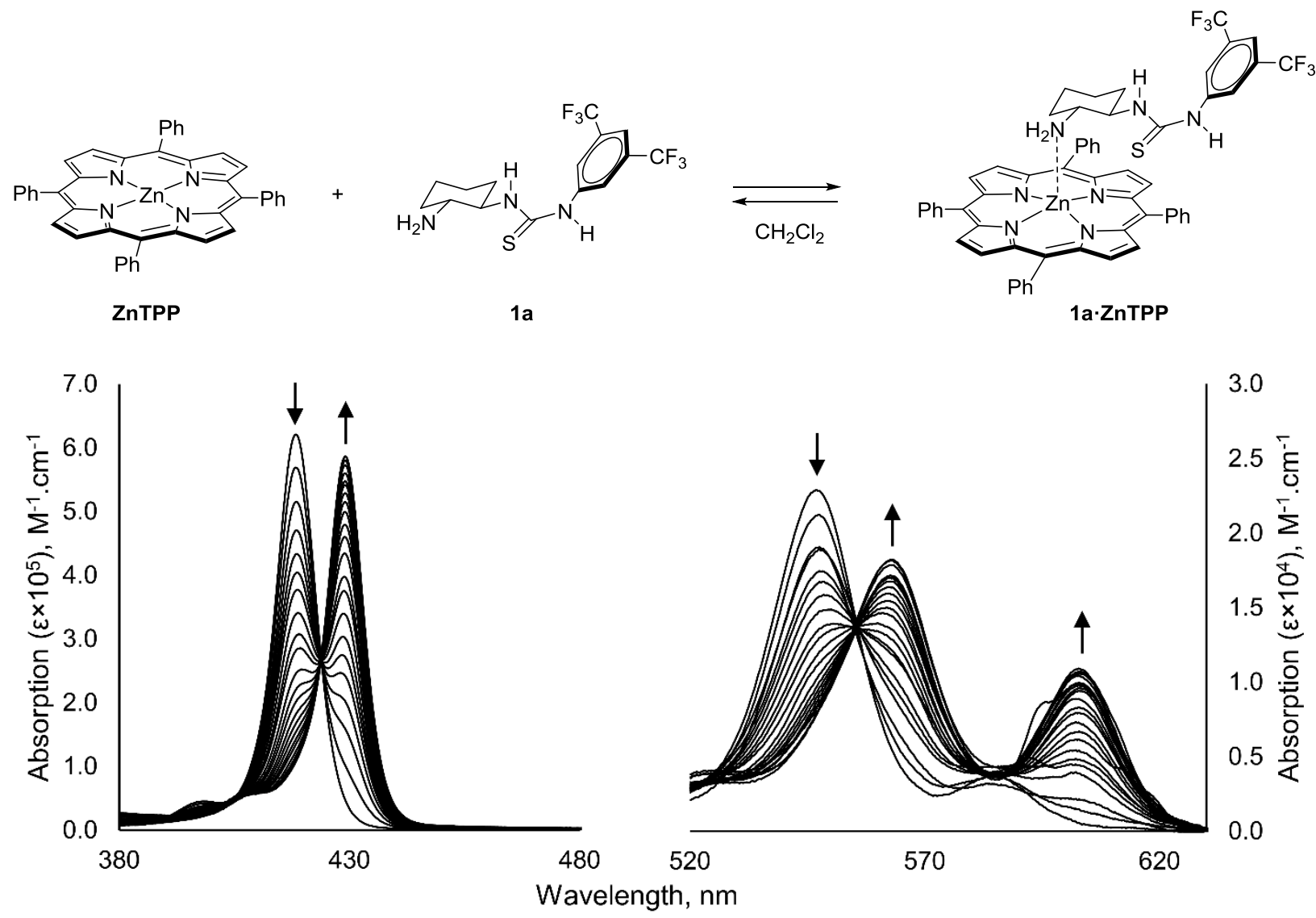

Fig. 1. Complexation of ZnTPP $\left(2.3 \times 10^{-6} \mathrm{M}\right)$ with 1a monitored by UV-Vis spectroscopy $\left(\mathrm{CH}_{2} \mathrm{Cl}_{2}\right.$ at $\left.293 \mathrm{~K}\right)$. Addition of 1 a $(0-7.4 \times$ $10^{-3} \mathrm{M}$ ) causes bathochromic shifts of ZnTPP Soret band (left) and Q bands (enlarged; right).

Table 1. Association constants $\left(K_{a}\right)$, Hammett substituents constants for phenyl groups of 1a-c ( $\left.\sigma_{\text {meta }}\right)$, and absorption maxima in UV-Vis spectra for 1:1 complexes of thioureas 1a-c with zinc porphyrins.

\begin{tabular}{cccccc}
\hline Guest & $\sigma_{\text {meta }}{ }^{a}$ & Porphyrin host & $\lambda$ max, nm $(\log \varepsilon)$ & $K_{\mathrm{a}}, \mathrm{M}^{-1}\left(\right.$ in $\mathrm{CH}_{2} \mathrm{Cl}_{2}$ at $\left.293 \mathrm{~K}\right)$ & $\log K_{\mathrm{a}}$ \\
\hline 1a & 0.43 & ZnTPP & $429.0(5.77), 563.2(4.26), 602.8(4.03)$ & $(2.30 \pm 0.04) \times 10^{3}$ & 3.36 \\
& & ZnOEP & $413.8(5.64), 540.8(4.38), 577.2(4.24)$ & $533 \pm 8$ & 2.73 \\
1b & 0.00 & ZnTPP & $429.0(5.74), 563.4(4.23), 603.0(3.98)$ & $(7.640 \pm 0.003) \times 10^{3}$ & 3.88 \\
1c & -0.069 & ZnTPP & $429.0(5.77), 563.4(4.26), 603.2(4.02)$ & $(1.166 \pm 0.006) \times 10^{4}$ & 4.07
\end{tabular}

${ }^{a}$ For the substituents in aryls of the guests 1a-c, according to ref. [38].

As expected, similar complexation experiment performed with less electron-deficient porphyrin ZnOEP afforded a noticeably smaller association constant $K_{\mathrm{a}}=533 \mathrm{M}^{-1}$ (Table 1). In comparison to 1a, phenyl- and 3,5-dimethylphenyl thioureas $(\mathbf{1 b}, \mathbf{1 c})$ are found to bind more strongly to ZnTPP, with values of $K_{\mathrm{a}}$ increasing in the order $\mathbf{1 a}<\mathbf{1 b}<\mathbf{1 c}$ (Table 1), in line 
with the enhancement of the electron-donating properties of the aryl substituents. This trend can be clearly visualised by using a Hammett plot (Fig. 2), and agrees with a predominantly electrostatic nature of the interaction, i.e. the zinc porphyrin host acts as a Lewis acid while the nitrogen donor in 1a serves as a base [36b, 37, 39].

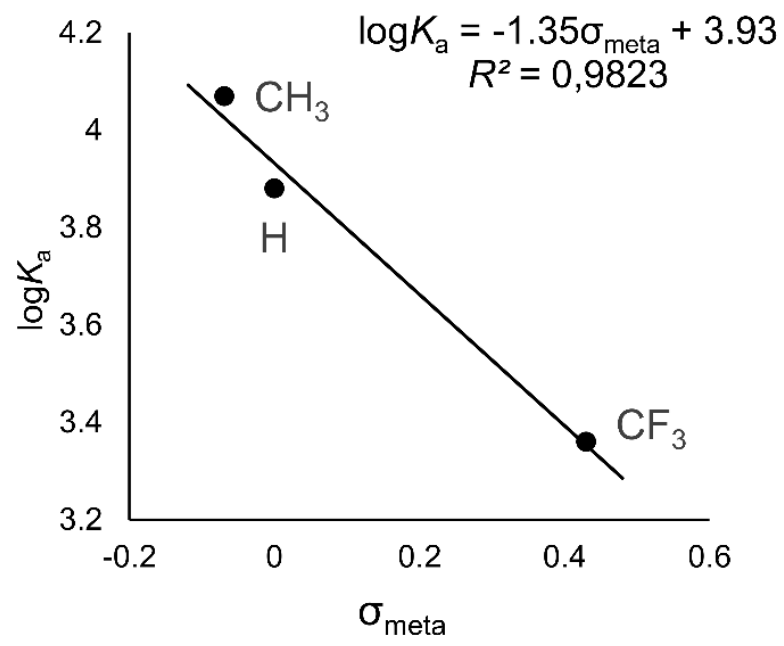

Fig. 2. Hammett plot of $\log K_{\mathrm{a}}$ vs $\sigma_{\text {meta }}$ constants for coordination of the guests 1a-c to ZnTPP.

\section{Circular dichroism spectra}

$\mathrm{CD}$ spectra of the complexes between zinc porphyrins and $\mathbf{1}$ were measured in $\mathrm{CH}_{2} \mathrm{Cl}_{2}$ as a solvent with a 2000 fold excess of 1. While parent ZnTPP is achiral and therefore CD silent, a noticeable CD signal was induced in the region of the porphyrin Soret band upon mixing with $(R, R)$-1a (Fig. 3, B). The observed CD profile consists of weak positive and relatively strong negative Cotton effects (CEs) at 436 and $428 \mathrm{~nm}$, respectively. Induced CD signals were also observed for the other hostguest systems, although the chiroptical outcome was different. For example, coordination of $(R, R)-\mathbf{1 a}$ to ZnOEP produced a negative $\mathrm{CE}$ at $414 \mathrm{~nm}$, while coordination of $(R, R)$-thioureas $\mathbf{1 b}$ and $\mathbf{1 c}$ to ZnTPP induced a positive CE at $\sim 430 \mathrm{~nm}$ (Fig. 3, C-E). As expected, $(S, S)$-enantiomer of 1a produced mirror-imaged CD signals in the Soret region of zinc porphyrins' absorption compared to its $(R, R)$-counterpart (Fig.3, B and C). These spectral changes clearly indicated that the chirality transfer process from chiral guests 1a-c to achiral zinc porphyrin hosts takes place. In order to rationalize the chirogenic mechanism, corresponding computational studies have been performed for the $(R, R)$-1a $\cdot \mathrm{ZnTPP}$ complex as a representative example exhibiting the most prominent $\mathrm{CD}$ outcome. 

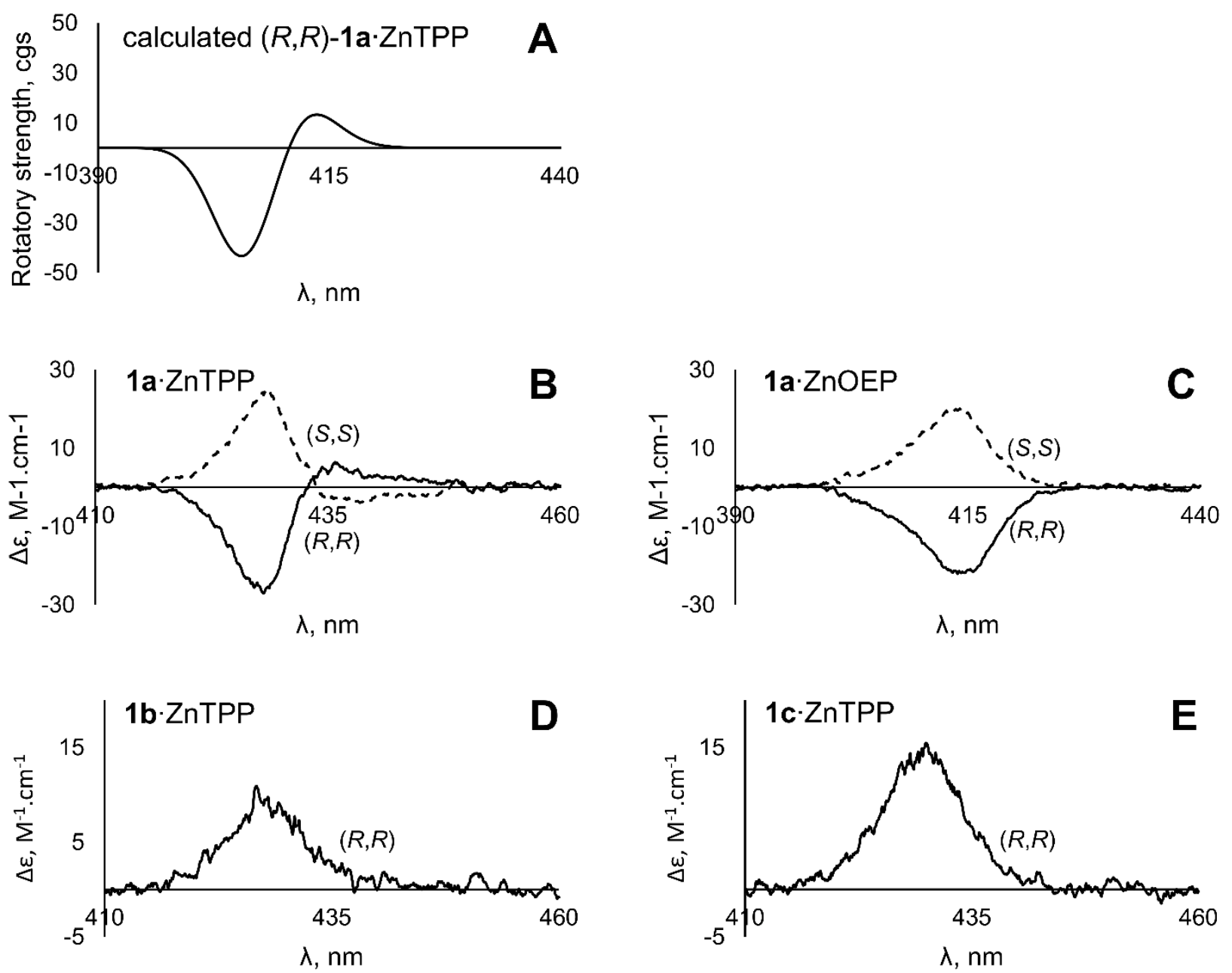

Fig. 3. Calculated (A) and experimental (B-E) CD spectra of 1:1 complexes between $(1 R, 2 R)$-2-aminocyclohexyl thioureas 1a-c and zinc porphyrins $\left(\mathrm{CH}_{2} \mathrm{Cl}_{2}, 293 \mathrm{~K}\right)$.

\section{The results of computational studies}

The six lowest-energy conformers have been optimized for the complex of 1a and ZnTPP (Table 2). According to the Boltzmann distribution at $295 \mathrm{~K}$, two major conformers III and $\mathbf{V}$ constitute $48.9 \%$ and $24.5 \%$ of the mixture, respectively. The remaining four conformers do not exceed $11 \%$ each. Zinc is pentacoordinated and shifted out of the mean porhyrin plane (defined by the four pyrrole $\mathrm{N}$ atoms) by $\sim 0.3-0.4 \AA$ towards the nitrogen atom of the guest, with the distance to the latter within $2.129-2.198 \AA$ in the different conformers. These structural parameters are typical for the complexes of ZnTPP with nitrogen donor ligands and indicate on ion-dipole character of the $\mathrm{Zn}-\mathrm{N}$ bond between the host and guest molecules [40]. More importantly, coordination of chiral guest 1a induces slight asymmetric twist of the porphyrin plane. The derrogation of symmetry can be characterized, for example, by dissimilar bonding distances to zinc from the four pyrrole nitrogens (e.g. for conformer III: $2.076,2.084,2.065$ and $2.122 \AA$ ) and slight tilting of the pyrrole ring out of the mean porhyrin plane. 
<smiles>N[C@@H]1CCCC[C@H]1NC(=S)Nc1cc(C(F)(F)F)cc(C(F)(F)F)c1</smiles>

anti-anti (aa)<smiles>N[C@@H]1CCCC[C@H]1NC(=S)Nc1cc(C(F)(F)F)cc(C(F)(F)F)c1</smiles>

anti-syn (as)<smiles>N[C@@H]1CCCC[C@H]1NC(=S)Nc1cc(C(F)(F)F)cc(C(F)(F)F)c1</smiles>

syn-anti (sa)

Scheme 2. Rotamers of thiourea 1a.

For the guest molecule 1a, three configurations can be distinguished due to rotations along the $\mathrm{N}-\mathrm{C}(=\mathrm{S})$ bonds (Scheme 2), denoted as anti-anti (aa), anti-syn (as) and syn-anti (sa) rotamers. In complex with ZnTPP, 1a mostly adopts the syn-anti configuration and only 8.6\% (conformers IV and VI) represent the less favourable [41] anti-anti rotamer; no anti-syn rotamers is present. Another notable structural feature is a $\pi$ - $\pi$ interaction between the bis-3,5-(trifluoromethyl)phenyl ring of the guest and phenyl ring of the host $[42,43]$. The two most abundant conformers III and $\mathbf{V}$ display nearly parallel-displaced (angle $>$ $30^{\circ}$ ) aromatic rings with a slight offset of the electron-windrawing 3,5-(trifluoromethyl)phenyl group and the distance between the rings centroids within $4.1 \AA$ (Fig. 4, A). On the contrary, the less-populated conformers (e.g. II) have the same rings in a edge-to-face orientation, with the bis-3,5-(trifluoromethyl)phenyl ring tilted around $65^{\circ}$ from the phenyl ring plane and the distance between the ring centroids of about $4.8 \AA$ (Fig. 4, B).

Table 2. Calculated relative energies, abundances (at $295 \mathrm{~K}$ ), and selected structural parameters for six lowest-energy conformers of the 1a.ZnTPP complex. ${ }^{a}$

\begin{tabular}{|c|c|c|c|c|c|c|}
\hline \multirow{2}{*}{ Conformer } & \multirow{2}{*}{$\begin{array}{c}\Delta \mathrm{E} \\
\mathrm{kcal} . \mathrm{mol}^{-1}\end{array}$} & \multirow{2}{*}{$\begin{array}{l}\text { Abundance, \% } \\
\text { (at } 295 \mathrm{~K} \text { ) }\end{array}$} & \multirow{2}{*}{$\begin{array}{l}\text { Configuration of } \\
\text { thiourea moiety }\end{array}$} & \multicolumn{3}{|c|}{ Aryl-aryl interaction ${ }^{b}$} \\
\hline & & & & Type & Distance $^{c}, \AA$ & Angle $^{d}$ \\
\hline I & 0.9 & 10.6 & $s a$ & edge-to-face & 4.8 & $65^{\circ}$ \\
\hline II & 1.1 & 7.3 & sa & edge-to-face & 4.8 & $67^{\circ}$ \\
\hline III & 0.0 & 48.9 & sa & face-to-face & 3.8 & $20^{\circ}$ \\
\hline IV & 1.5 & 4.0 & $a a$ & edge-to-face & 4.8 & $65^{\circ}$ \\
\hline $\mathbf{V}$ & 0.4 & 24.5 & sa & face-to-face & 4.1 & $30^{\circ}$ \\
\hline VI & 1.4 & 4.6 & $a a$ & edge-to-face & 4.8 & $65^{\circ}$ \\
\hline
\end{tabular}

${ }^{a}$ Calculated using B3LYP-D3BJ/cc-pVDZ// WB97XD/cc-pVTZ + SMD $\left(\mathrm{CH}_{2} \mathrm{Cl}_{2}\right)$ level of theory.

${ }^{b}$ Interactions between phenyl ring of the host and bis-3,5-( $\left.\mathrm{CF}_{3}\right)$ phenyl of the guest.

${ }^{c}$ Approximate distance between the ring centroids.

${ }^{d}$ Angle between the ring planes. 
A)

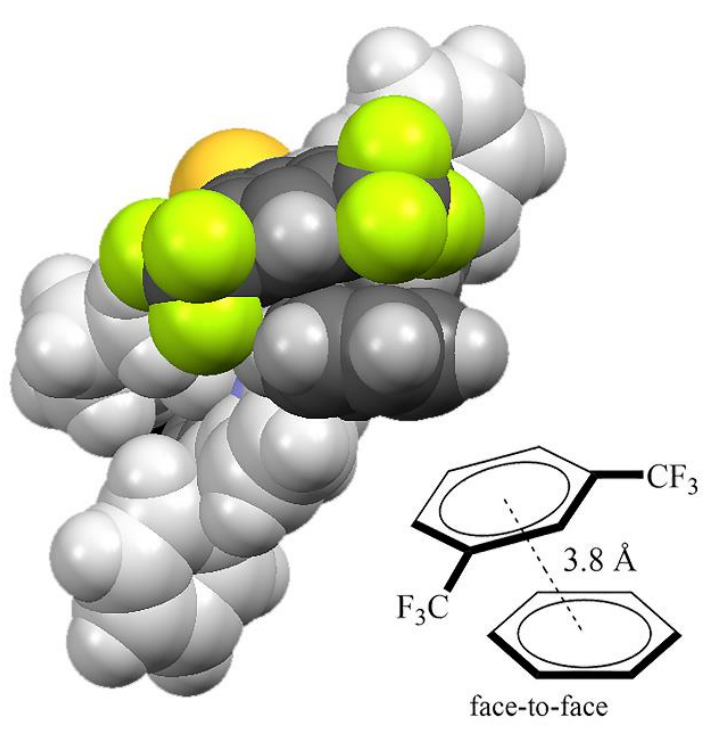

B)

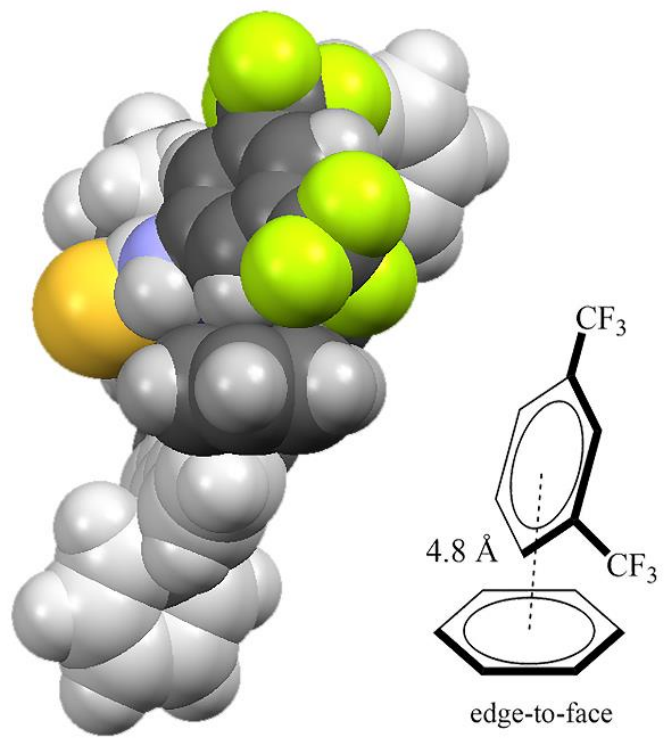

Fig. 4. Space-filled models of the conformer III (A) and conformer II (B) displaying different modes of the $\pi$ - $\pi$ interaction of the aryl groups in the host and guest molecules.

Simulated CD spectra for each individual conformers and the resulting CD spectra are presented in Figures 5 and 3 (A). The calculated UV-Vis spectrum, values of oscillator strengths, rotational forces, and wavelengths are given in the Supporting Information.

Metalloporphyrins possess a characteristic UV-Vis spectrum with a strong absorption band (Soret band) in the high energy region of the optical spectrum and two weak Q bands in the low energy area due to the corresponding $S_{2} \leftarrow S_{0}$ and $S_{1} \leftarrow S_{0}$ transitions [44]. The calculated UV-Vis spectrum (Fig. S26, Supporting Information) is in agreement with the experimental spectrum. The Q absorption band at $\lambda=605 \mathrm{~nm}$ corresponds to the partially forbidden $S_{1} \leftarrow S_{0}$ transition of low intensity, while the Soret band at $\lambda=407 \mathrm{~nm}$ is very intense and corresponds to the allowed $S_{2} \leftarrow S_{0}$ transition. The main contributors to these electronic transitions are $\pi$ and $\pi^{*}$ orbitals delocalized on the porphyrin plane (Fig. S25, Supporting Information). Coordination of 1a to the $D_{4 h}$-symmetric porphyrin leads to derogation of the symmetry and eliminates degeneracy of the exited electronic states, which results in splitting of the absorption bands. For the most stable conformer III, $4.8 \mathrm{~nm}$ splitting for the Q band and $1.8 \mathrm{~nm}$ for the Soret band have been found. 

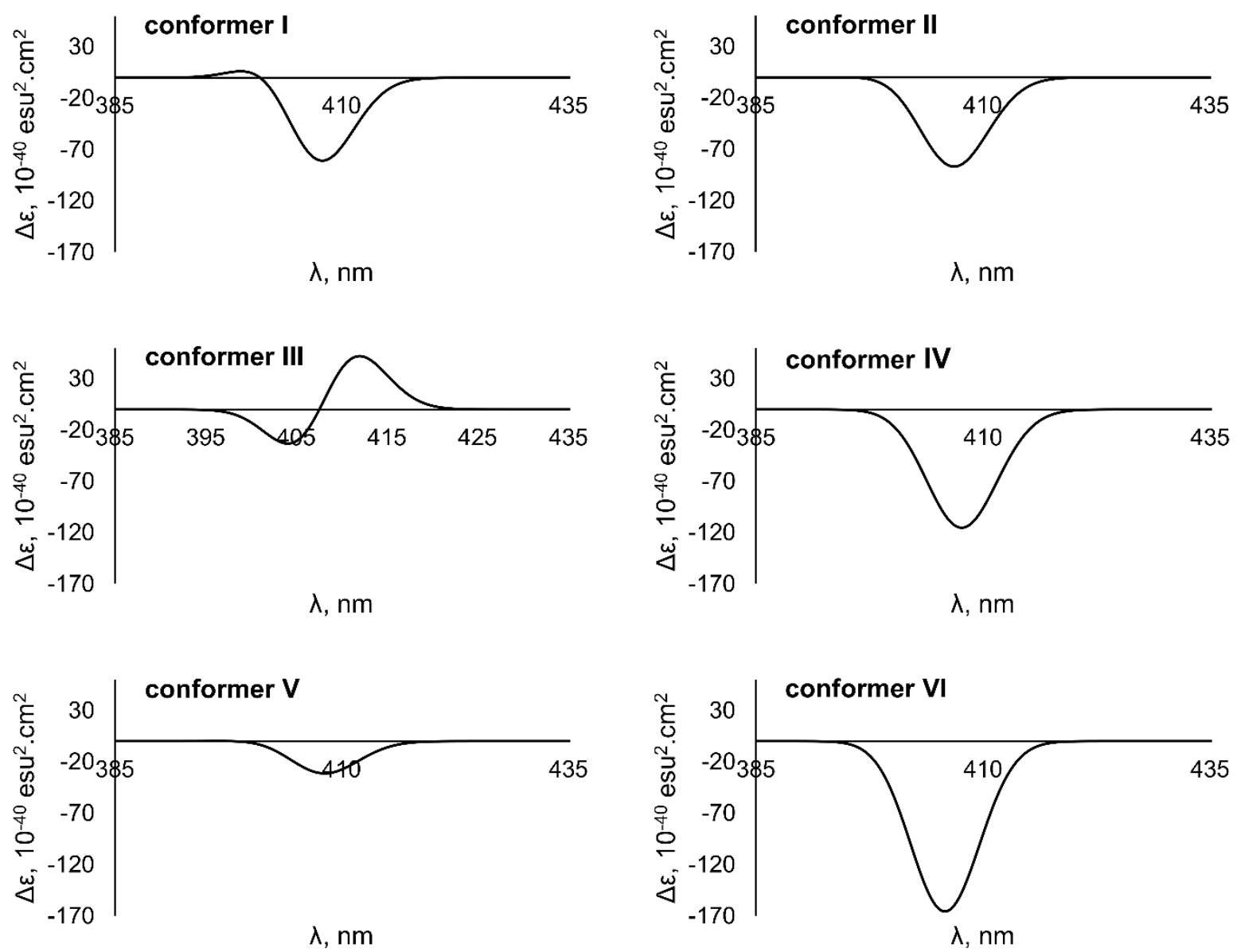

Fig. 5. Calculated CD spectra for individual conformers of $(R, R)-\mathbf{1 a} \cdot \mathrm{ZnTPP}$ complex.

Partial derogation of the porphyrin symmetry leads to reorientation of the electric and magnetic transition dipole moments and causes an unequal response of the system to the left and right-polarized optical radiations. For example, the negative rotatory strength corresponding to the angle of 92 degrees between the electric and magnetic dipole moments and a positive value consistent with the angle of 88 degrees have been found for the lowest energy conformer III. Similar effects have been observed for other conformers. Only the most populated conformer III displays a bisignate positive Cotton effect (Fig. 5) corresponding to the $S_{2} \leftarrow S_{0}$ transition (Soret band), while the other conformers produce negative CD signals of various intensity, thus indicating that the sign and shape CD signals are conformer-dependent.

The simulated CD spectrum of the $(R, R)-\mathbf{1 a} \cdot \mathrm{ZnTPP}$ system (Fig. 3, A), calculated as Boltzmann weighted average of CD spectra for each conformer, is in a good agreement with the experimental one (Fig. 3, B). The shape of the experimentally observed CD signal is quite accurately reproduced in the calculated spectrum, with the absorption maxima shifted by about $20 \mathrm{~nm}$ to shorter wavelength in comparison with experimental values.

This result validates the accuracy of the computational approach, thus indicating that the computed structures and conformer abundances of 1a.ZnTPP are accurate enough to describe the complex. Although the chiroptical outcome is different for the other host-guest systems described here (Fig. 3, C-E), the induced CD signals are presumably generated via the same chirogenic mechanism. The observed deviations are apparently a result of the variations in asymmetrical deformation of the porphyrin core produced by chiral guests 1a-c and different distribution of the conformers existing in the host-guest 
systems. Further computational and experimental studies are currently in progress in our laboratory to confirm the generality of the proposed chirality transfer mechanism in these supramolecular assemblies.

\section{CONCLUSIONS}

Here, we describe for the first time the complexation process between $(1 R, 2 R)$-2-aminocyclohexyl arylthioureas 1a-c as chiral guests and zinc porphyrins as achiral hosts. It was found that coordination of $\mathbf{1 a - c}$ occurs through the more electrondonating amino nitrogen atom to produce the corresponding 1:1 complexes, while the more electron-deficient thiocarbonyl group has low binding affinity to zinc porphyrins. The values of association constants generally increase with increased the electron-withdrawing properties of the host (ZnTPP $>$ ZnOEP) and electron-donating ability of the guest $(\mathbf{1 a}<\mathbf{1 b}<\mathbf{1 c})$, hence indicating predominantly an electrostatic (Lewis acid-base) nature of the interaction. Induced CD signal in the absorption region of the porphyrin Soret band have been observed for all host-guest systems, although the chiroptical outcome was specific for a given host-guest combination. Computational studies performed for $(R, R)$-1a $\cdot \mathrm{ZnTPP}$ revealed Zn-N cationdipole interaction, slight asymmetric bending of the porphyrin plane, preference for the syn-anti configuration of the thiourea moiety, and existence of the secondary $\pi-\pi$ interactions between the host and guest molecules. The calculated CD spectrum for $(R, R)-1 \mathbf{a} \cdot Z n T P P$ complex is in good agreement with the experimental data, thus validating the accuracy of the computational approach and rationalizing the chirogenic mechanism.

\section{Acknowledgements}

This research was supported by the H2020-FETOPEN 828779 INITIO project. N.K., D.M. and D.K. gratefully acknowledge support from Tallinn University of Technology (Grant No. B58) and Dora Plus program. I.O. acknowledges support from Estonian ministry of education and research (Grant No. PUTJD749). J.A. is grateful to funding through PRG399 by the Estonian Research Council and CoE TK134 by the European Regional Development Fund. V.B. acknowledges the start-up research grant (YZZ16005) from South-Central University for Nationalities (Wuhan, China). Computations were performed on the HPC cluster at Tallinn University of Technology, which is part of the ETAIS project. Dr. Lukaš Ustrnul (Tallinn University of Technology) is kindly acknowledged for assisting with CD measurements.

\section{Supporting Information}

${ }^{1} \mathrm{H}$ and ${ }^{13} \mathrm{C}$ NMR data for compounds 1a-c; ${ }^{1} \mathrm{H}$ NMR and UV-Vis titration experiments (raw data, curve fittings and residuals analysis); CD spectra; detailed results of computational studies (Cartesians and energies for conformers I-VI; values of the oscillator strengths, rotational forces and wavelengths; calculated UV-Vis spectrum for 1a·ZnTPP complex). This material is available free of charge via the internet at http://www.worldscinet.com/jpp/jpp.shtml.

\section{REFERENCES}

1. Paolesse R, Nardis S, Monti D, Stefanelli M, Di Natale C. Chem. Rev. 2017; 117: 2517-2583.

2. (a) D'Amico A, Di Natale C, Paolesse R, Macagnano A, Mantini A. Sens. Actuator B-Chem. 2000; 65: 209-215; (b) Di Natale C, Macagnano A, Davide F, D’Amico A, Paolesse R, Boschi T, Faccio M, Ferri G. Sens. Actuator B-Chem. 1997; 44: 521-526. 
3. (a) Hembury GA, Borovkov VV, Inoue Y. Chem. Rev. 2008; 108: 1-73; (b) Borovkov VV, Hembury GA, Inoue Y. Acc. Chem. Res. 2004; 37: 449-459; (c) Borovkov V, Symmetry 2014; 6: 256-294.

4. Mizutani T, Ema T, Yoshida T, Kuroda Y, Ogoshi H. Inorg. Chem. 1993; 32: 2072-2077.

5. Borovkov VV, Lintuluoto JM, Inoue Y. J. Am. Chem. Soc. 2001; 123: 2979-2989.

6. Borovkov VV, Lintuluoto JM, Sugeta H, Fujiki M, Arakawa R, Inoue Y. J. Am. Chem. Soc. 2002; 124: 2993-3006.

7. (a) Huang X, Fujioka N, Pescitelli G, Koehn FE, Williamson T, Nakanishi K, Berova N. J. Am. Chem. Soc. 2002; 124: 10320-10335; (b) Anyika M, Gholami H, Ashtekar KD, Acho R, Borhan B. J. Am. Chem. Soc. 2014; 136: 550-553.

8. Lintuluoto JM, Borovkov VV, Inoue Y. J. Am. Chem. Soc. 2002; 124: 13676-13677.

9. Borovkov VV, Yamamoto N, Lintuluoto JM, Tanaka T, Inoue Y. Chirality 2001; 13: 329-335.

10. Borovkov VV, lintuluoto JM, Hembury GA, Sugiura M, Arakawa R, Inoue Y. J. Org. Chem. 2003; 68: 7176-7192.

11. Okino T, Hoashi Y, Takemoto Y. J. Am. Chem. Soc. 2003; 125: 12672-12673.

12. Takemoto Y. Org. Biomol. Chem. 2005; 3: 4299-4306.

13. Taylor MS, Jacobsen EN. Angew. Chem. Int. Ed. 2006; 45: 1520-1543.

14. Custelcean R. Chem. Commun. 2008; 295-307.

15. (a) Milgram BC, Eskildsen K, Richter SM, Scheidt WR, Scheidt KA. J. Org. Chem. 2007; 72: 3941-3944; (b) Borovkov VV, Lintuluoto JM, Inoue Y. Helv. Chim. Acta 1999; 82: 919-934; (c) Kojima T, Nakanishi T, Honda T, Harada R, Shiro M, Fukuzumi S. Eur. J. Inorg. Chem. 2009; 727-734; (d) Speck M, Niethammer D, Senge MO, J. Chem. Soc., Perkin Trans. 2, 2002; 455-462.

16. (a) Dudziński K, Pakulska AM, Kwiatkowski P. Org. Lett. 2012; 14: 4222-4225; (b) Zhang XJ, Liu SP, Lao JH, Du GJ, Yan M, Chan ASC. Tetrahedron: Asymmetry 2009; 20: 1451-1458.

17. (a) Thordarson P. Chem. Soc. Rev. 2011; 40: 1305-1323; (b) Hirose K. J. Incl. Phenom. Macrocycl. Chem. 2001; 39: 193209.

18. Hibbert DB, Thordarson P. Chem. Commun. 2016; 52: 12792-12805.

19. Mack J, Asano Y, Kobayashi N, Stillman M. J. J. Am. Chem. Soc. 2005; 127: 17697-17711.

20. Bouř P, Záruba K, Urbanová M, Setnička V, Matějka P, Fiedler Z, Král V. Chirality 2000; 12: 191-198.

21. TURBOMOLE V6.5 2013, a development of University of Karlsruhe and Forschungszentrum Karlsruhe GmbH, 19892007, TURBOMOLE GmbH, since 2007; available from http://www.turbomole.com.

22. Becke, AD. Phys. Rev. A 1988; 38: 3098-3100.

23. (a) Perdew J. P. Phys. Rev. B 1986; 33: 8822-8824; (b) Grimme S, Antony J, Ehrlich S, Krieg H. J. Chem. Phys. 2010; 132: 154104; (c) Schäfer A, Horn H, Ahlrichs R. F. J. Chem. Phys. 1992; 97: 2571-2577.

24. (a) Eichkorn K, Treutler O, Öhm H, Häser M, Ahlrichs R. Chem. Phys. Lett. 1995; 240: 283-290; (b) Eichkorn K, Weigend F, Treutler O, Ahlrichs R. Theor. Chem. Acc. 1997; 97: 119-124; (c) Sierka M, Hogekamp A, Ahlrichs R. J. Chem. Phys. 2003; 118: 9136-9148.

25. Frisch MJ, Trucks GW, Schlegel HB, Scuseria GE, Robb MA, Cheeseman JR, Scalmani G, Barone V, Petersson GA, Nakatsuji H, Li X, Caricato M, Marenich AV, Bloino J, Janesko BG, Gomperts R, Mennucci B, Hratchian HP, Foresman JB, Fox DJ. Gaussian 16, Revision B.01. (2016).

26. (a) Lee C, Yang W, Parr RG. Phys. Rev. B 1988; 37: 785-789; (b) Miehlich B, Savin A, Stoll H, Preuss H. Chem. Phys. Lett. 1989; 157: 200-206; (c) Becke AD. J. Chem. Phys. 1993; 98: 1372-1377; (d) Grimme S, Ehrlich S, Goerigk L. J. Comput. Chem. 2011; 32: 1456-1465. 
27. (a) Kendall RA, Dunning TH, Harrison RJ. J. Chem. Phys. 1992; 96: 6796-6806; (b) Dunning TH. J. Chem. Phys. 1989; 90: 1007-1023; (c) Woon DE, Dunning TH. J. Chem. Phys. 1993; 98: 1358-1371.

28. (a) Dhamija A, Saha B, Rath SP. Inorg. Chem. 2017; 56: 15203-15215; (b) Arkan F, Izadyar M. Mater. Chem. Phys. 2017; 196: 142-152; (c) Si Y, Yang G. RSC Adv. 2013; 3: 2241-2247.

29. Chai JD, Head-Gordon M. Phys. Chem. Chem. Phys. 2008; 10: 6615-6620;

30. Marenich AV, Cramer CJ, Truhlar DG. J. Phys. Chem. B 2009; 113: 6378-6396.

31. (a) Bauernschmitt R, Ahlrichs R. Chem. Phys. Lett. 1996; 256: 454-464; (b) Stratmann RE, Scuseria GE, Frisch MJ. J. Chem. Phys. 1998; 109: 8218-8224; (c) Casida ME, Jamorski C, Casida KC, Salahub DR. J. Chem. Phys. 1998; 108: 4439-4449.

32. Jang H, Kim NJ, Heo J. Comput. Theor. Chem. 2018; 1125: 63-68.

33. Andreev VP, Sobolev PS, Zaitsev DO, Tafeenko VA. Russ. J. Gen. Chem. 2014; 84: 320-325.

34. (a) Salter MH, Reibenspies JH, Jones SB, Hancock RD. Inorg. Chem. 2005; 44: 2791-2797; (b) Malik MR, Vasylyeva V, Merz K, Metzler-Nolte N, Saleem M, Ali S, Isab AA, Munawar KS, Ahmad S. Inorganica Chim. Acta 2011; 376: 207-211; (c) Eaton DR, Zaw K. J. Inorg. Nucl. Chem. 1976; 38: 1007-1010; (d) Schafer M, Curran C. Inorg. Chem. 1966; 5: 265-268.

35. Liu S, Lei Y, Yang Z, Lan Y. J. Mol. Struct. 2014; 1074: 527-533.

36. (a) Nappa M, Valentine JS. J. Am. Chem. Soc. 1978; 100: 5075-5080; (b) Vogel GC, Stahlbush JR. Inorg. Chem. 1977; 16: 950-953; (c) Hartle MD, Tillotson MR, Prell JS, Pluth MD. J. Inorg. Biochem. 2017; 173: 152-157; (d) Hartle MD, Sommer SK, Dietrich SR, Pluth MD. Inorg. Chem. 2014; 53: 7800-7802.

37. Vogel GC, Searby LA. Inorg. Chem. 1973; 12: 936-939.

38. Hansch C, Leo A, Taft RW. Chem. Rev. 1991; 91: 165-195.

39. Vogel GC, Beckmann BA. Inorg. Chem. 1976; 15: 483-484.

40. See, for example: (a) Kumar RK, Diskin-Posner I, Goldberg I. J. Incl. Phenom. Macrocycl. Chem. 2000; 37: 219-230. (b) Andreev VP, Sobolev PS, Zaitsev DO, Remizova LA, Tafeenko VA. Russ. J. Gen. Chem. 2014; 84: 1979-1988. (c) Diskin-Posner Y, Patra GK, Goldberg I. J. Chem. Soc., Dalton Trans. 2001; 2775-2782. (d) Ghanbari B, Shahhoseini L, Kubicki M. Polyhedron 2017; 133: 419-432.

41. Kreienborg NM, Merten C. Chem. - A Eur. J. 2018; 24: 17948-17954.

42. Janiak C. J. Chem. Soc., Dalton Trans., 2000; 3885-3896.

43. Martinez CR, Iverson BL. Chem. Sci. 2012; 3: 2191-2201.

44. Gouterman M. The Porphyrins, Dolphin, D., Vol. 3, Ed. Academic Press: London, 1978; 1-165. 